\title{
Survey On Disclosing Information To Children With Genetic Conditions And Their Siblings In Japan
}

\section{Mikiko Kaneko}

Saitama Children's Medical Center

Daijyu Oba

Saitama Children's Medical Center

Hirofumi Ohashi ( $\nabla$ ohashih@peach.ocn.ne.jp )

Saitama Children's Medical Center

\section{Research Article}

Keywords: disclosing information, genetic condition, genetic counseling

Posted Date: November 17th, 2021

DOI: https://doi.org/10.21203/rs.3.rs-1046073/v1

License: (1) This work is licensed under a Creative Commons Attribution 4.0 International License.

Read Full License 


\section{Abstract}

Many parents face the dilemma of when, how, and what to disclose to their children regarding their genetic conditions. The purpose of this study was to learn about the experiences of parents regarding disclosing information to their children with genetic conditions.

Methods: A questionnaire was sent to 378 parents of children and adolescents with the following genetic conditions: 22q11.2 deletion syndrome, Beckwith-Wiedemann syndrome, Noonan syndrome, RussellSilver syndrome, Kabuki syndrome, Williams syndrome, Prader-Willi syndrome, and Sotos syndrome. Findings were analyzed using descriptive statistics for multiple-choice questions and thematic analysis for open-ended questions.

Results: Of the parents surveyed, $158(41.8 \%)$ responded to the questionnaires. The average age of children with genetic conditions was 12 years. Sixty-seven parents had disclosed relevant information to their children, whereas 91 had not. Sixty-eight out of 91 respondents were planning to disclose information in the future. Many respondents who had disclosed information did not regret this. They felt good talking about genetic conditions, and had talked about genetic conditions with the affected children following disclosure.

Conclusion: This study contributed to our understanding of the attitudes of parents towards disclosing information to children with genetic conditions.

\section{Introduction}

Following the diagnosis of a child with a genetic condition, parents face the challenge of disclosing the nature of the condition with their affected child. Many parents face the dilemma of when, how, and what to disclose to their children about their genetic conditions [1], [2], [3]. Most parents express emotions such as anxiety, worry, and concern, with many relying on their own experiences regarding a genetic condition in the family for informing their own children [4]. Parents who did not share any information tended to evaluate their children as being too young or immature to understand the information [2]. However, disclosing information to children about their genetic condition is important if the affected children are to lead autonomous and independent lives in the future.

It has been shown that children who gradually learned about their conditions as they grew up could more efficiently cope and come to terms with the risks of either to themselves or to other family members [5]. Parents and adolescents said that receiving information about their genetic conditions as children was less shocking, and even more so when they were gradually informed of all associated aspects as they grew up [6]. Therefore, disclosing such information from an early age is important and helps children understand the nature of their health condition and its more efficient management.

However, there have been no reports on the number of parents who did not wish to share or will not share such information with their children in Japan. It has also been difficult to grasp the perspectives of 
parents regarding the disclosure of such information to their children. Therefore, we conducted a questionnaire survey to investigate the experiences and attitudes of parents regarding the disclosure of medical information to children and adolescents with genetic conditions and learn the ways through which such information should be disclosed to children and their siblings. In this study, we focused on quantitative data.

\section{Methods}

\section{Editorial Policies and Ethical Considerations}

This study was approved by the Saitama Children's Medical Center Institutional Review Board (\#2019-02020) and all methods were performed in accordance with the relevant guidelines and regulations. All participants gave written informed consent when returning questionnaire.

\section{Design}

This study utilized both quantitative and qualitative approaches. We conducted a questionnaire survey between November and December 2019. The questionnaire was a combination of multiple-choice and free-response questions about the disclosure of information to children and adolescents with genetic conditions.

\section{Participants}

A number of group programs for genetic conditions have been conducted at the outpatient clinic of Saitama Children's Medical Center since 2000. Potential participants were identified through a list of families from these programs. Questionnaires were sent to 378 parents or caregivers of children with one of the following genetic conditions: 22q11.2 deletion syndrome (22qDS), Beckwith-Wiedemann syndrome (BWS), Noonan syndrome (NS), Russell-Silver syndrome (RSS), Kabuki syndrome (KS), Williams syndrome (WS), Prader-Willi syndrome (PWS), or Sotos syndrome (SS).

Inclusion criteria

Children who were less than 4 years old or who were diagnosed within one year of enrollment were excluded from the study.

\section{Measures}

A common questionnaire was prepared, by which all parents were asked whether they had disclosed information to their children (Table 1). If the answer was positive, the parents moved to Questionnaire I (Table 1). If the answer was negative, the parents moved to Questionnaire II (Table 1).

Table 1. Questionnaires 
Common questionnaire ${ }^{1}$

Q1 Name, relationship, and age of respondent

Q2 Name, sex, birth order, age, diagnosis, and age of diagnosis of child

Q3 Whether parents disclosed information or not

If yes, move to questionnaire I

If no, move to questionnaire II

Questionnaire $1^{2}$

Q1 The age of the child at disclosure

Q2 Who primarily carried out the disclosure?

Q3 Who was present other than the above persons?

Q4 Reasons for disclosure

Q5 Details and important points when disclosing

Q6 Whether or not the genetic condition was discussed after disclosure

Q7 Information that was helpful for disclosure

Q8 How did you feel after the disclosure?

Q9 Number of siblings of the child with a genetic condition

Q10 Whether parents disclosed information about genetic conditions to the siblings or not

Q11 The age of siblings at disclosure, who primarily carried out the disclosure, who was present, reasons, details, and important points when disclosing

Q12 Whether or not the genetic condition was discussed with the siblings after disclosure

Q13 Will you disclose to the siblings later, if you haven't yet?

Q14 When will you disclose to the siblings?

Q15 Your plan to disclose to the siblings: age at disclosure, who will primarily carry out the disclosure, who will be present, reasons, details, and important points when disclosing

Q16 Feelings, thoughts, and desires about disclosing information

Questionnaire $\|^{3}$

Q1 Reasons for avoiding disclosure

Q2 Whether or not you will disclose information in the future

Q3 If you plan on disclosing in the future: the age at disclosure, who will primarily carry out the disclosure, who will be present, reasons, details, and important points when disclosing 
Q4 Number of siblings of the child with a genetic condition

Q5 Whether parents disclosed information about genetic conditions to siblings or not

Q6 The age of siblings at disclosure, who primarily carried out the disclosure, who was present, reasons, details, and important points when disclosing, OR your plan to disclose information to the siblings

Q7 Feelings, thoughts, and desires about disclosing information

${ }^{1}$ All responders answered these questions.

${ }^{2}$ Responders who had disclosed information to their children answered these questions.

${ }^{3}$ Responders who had not disclosed information to their children answered these questions.

All questionnaires were provided along with an informed consent form. Upon consent, the parents participated in our study by returning the completed questionnaires together with the signed consent form.

Data analysis

We used descriptive statistics to analyze multiple-choice questions and thematic analysis to analyze open-ended questions. Thematic analysis is a method for identifying, analyzing, and reporting patterns within data, and thus minimally organizes and describes datasets in greater detail [7].

\section{Results}

\section{Information on respondents and their children}

Of the 378 parents, only 158 responded to the survey (response rate: $41.8 \%$ ). The respondents consisted of 128 mothers, 11 fathers, and 19 both parents. Most respondents were mothers $(n=128,81 \%)$. The average age of respondents was 45 years. The current age of children and their age at the time of diagnosis of their genetic condition were 12 years and 21 months old on average, respectively. Information on respondents and their children are shown in Tables 2. 
Table 2

Classification of responders, sex, diagnosis, and age of children, and number of siblings

\begin{tabular}{|c|c|c|c|c|}
\hline & $\%$ & $\mathrm{n}$ & Average age (range) & Age at diagnosis (range) \\
\hline Responders $(\mathrm{N}=158)$ & & & $45(25-65)$ & \\
\hline Father & 7 & 11 & & \\
\hline Mother & 81 & 128 & & \\
\hline Parents & 12 & 19 & & \\
\hline Diagnosis $^{1}$ & & 158 & $12(4-28)$ & $1.9(0-11)$ \\
\hline $22 q 11.2$ deletion syndrome & & 27 & $11(4-28)$ & $2.8(0-8)$ \\
\hline Beckwith-Wiedemann syndrome & & 19 & $14(4-28)$ & $0.5(0-1)$ \\
\hline Noonan syndrome & & 17 & $11(4-28)$ & $4.0(0-12)$ \\
\hline Russell-Silver syndrome & & 3 & $5(4-7)$ & $1.2(1-5)$ \\
\hline Kabuki syndrome & & 29 & $14(4-28)$ & $2.4(0-11)$ \\
\hline Williams syndrome & & 28 & $13(4-26)$ & $2.3(0-11)$ \\
\hline Prader-Willi syndrome & & 19 & $12(4-23)$ & $1.3(0-10)$ \\
\hline Sotos syndrome & & 16 & $11(4-24)$ & $1.5(0-8)$ \\
\hline Sex of child ${ }^{2}$ & & & $12(4-28)$ & \\
\hline Male & 58 & 91 & & \\
\hline Female & 42 & 67 & & \\
\hline \multicolumn{5}{|l|}{ Disclosure $^{2}$} \\
\hline Disclosed & 42 & 67 & & \\
\hline Not disclosed & 58 & 91 & & \\
\hline
\end{tabular}

${ }^{1}$ The diagnosis and age of each child with a genetic condition.

2 This number reflects children with genetic conditions.

${ }^{3}$ This number reflects the siblings of affected children. 


\begin{tabular}{|c|c|c|c|c|}
\hline & $\%$ & $\mathbf{n}$ & Average age (range) & Age at diagnosis (range) \\
\hline \multicolumn{5}{|l|}{ Siblings ${ }^{3}$} \\
\hline One or more siblings & 81 & 128 & & \\
\hline One sibling & & 91 & & \\
\hline Two siblings & & 34 & & \\
\hline Three siblings & & 3 & & \\
\hline No siblings & 19 & 30 & & \\
\hline \multicolumn{5}{|c|}{${ }^{1}$ The diagnosis and age of each child with a genetic condition. } \\
\hline \multicolumn{5}{|c|}{2 This number reflects children with genetic conditions. } \\
\hline
\end{tabular}

Of the 158 respondents, 67 (42\%) had disclosed information to their children regarding their genetic conditions, whereas 91 (58 \%) did not. Many children with BWS, RSS, and WS were informed, whereas many children with 22q11.2, Noonan, Kabuki, PWS, and Sotos syndromes were not (Figure 1). Of the 91 respondents who had not disclosed any information, 68 (75\%) answered that they wanted to inform their children about their genetic conditions in the future, while 23 (25\%) answered that they did not want to disclose this information in any way. One respondent stated that this was a matter of individuality, and thus there would be no merit in disclosing it. The most frequent reason for not disclosing this information was the intellectual disability of affected children. Of the 53 respondents who answered that their affected child had siblings, 46 had disclosed the genetic condition of the affected child to the siblings.

\section{Questionnaire I: Respondents who had disclosed information}

The most frequent answer regarding the time at which respondents talked to their affected children about their conditions for the first time was when their affected children were at preschool age (4-6 years). The second most frequent response was when children were around the fifth to sixth grades in elementary school (11-12 years). No one disclosed the information after the children had reached 19 years of age (Figure 2). Regarding the disclosure of such information to siblings, preschool age (4-6 years) was also the most frequent response. However, inability to remember when they first informed the siblings was the second most frequent response (Figure 2).

Concerning the affected children, the mother was the primary person disclosing the diagnosis $(n=35 ; 50$ $\%)$. Disclosure by both parents was the second most frequent answer $(n=25 ; 36 \%)$, whereas disclosure by the father constituted only $3 \%(n=2)$ of answers. Finally, sources other than parents, such as doctors, group meetings, and illustrated books, constituted $10 \%(n=7)$ of answers. 
Regarding siblings, mothers were the ones that primarily disclosed the relevant information $(n=35 ; 64$ $\%)$. Disclosure by both parents was the next most frequent answer $(n=12 ; 22 \%)$, followed by disclosure by other sources, such as doctors, grandmothers, or group meetings $(n=5 ; 9 \%)$ and fathers $(n=3 ; 5 \%)$.

We asked respondents to select all the reasons behind their decision to reveal the diagnosis to their children (Table 3). Respondents were also asked to write down any additional reasons they might have had.

Table 3

Reasons for disclosure

\begin{tabular}{|c|c|c|c|c|c|}
\hline \multirow[b]{2}{*}{ Items } & & \multicolumn{2}{|c|}{$\begin{array}{l}\text { Children with genetic } \\
\text { condition }(n=67)\end{array}$} & \multicolumn{2}{|c|}{$\begin{array}{l}\text { Siblings }^{1} \\
(n=46)\end{array}$} \\
\hline & & $\%$ & $\mathrm{n}$ & $\%$ & $\mathrm{n}$ \\
\hline 1 & Asked about the symptoms & 13 & 9 & 16 & 8 \\
\hline 2 & Asked why he/she visited the hospital & 25 & 17 & 30 & 15 \\
\hline 3 & Thought he/she was old enough to understand & 30 & 20 & 44 & 22 \\
\hline 4 & $\begin{array}{l}\text { Wanted him/her to understand why he/she visited the } \\
\text { hospital as a result of disclosing information }\end{array}$ & 43 & 29 & 36 & 18 \\
\hline 5 & Seemed to be concerned about physical symptoms & 7 & 5 & 10 & 5 \\
\hline 6 & Because his/her friends said something & 10 & 7 & 14 & 7 \\
\hline 7 & $\begin{array}{l}\text { Because of an event, such as enrollment, employment, } \\
\text { or marriage. }\end{array}$ & 16 & 11 & 12 & 6 \\
\hline 8 & Other (if possible, please explain in detail) & 37 & 25 & 26 & 13 \\
\hline Note a & ems were multiple-choice answers. & & & & \\
\hline
\end{tabular}

The most common reason was that respondents wanted their affected children to understand the reason for their more frequent visits to the hospital compared with their peers $(n=29 ; 43 \%)$. The next most frequent reason was that children were mature enough to understand $(n=20 ; 30 \%)$. Apart from the above, other answers that respondents provided included the following: "I want him/her to know and understand him/herself", "he/she will have to have strength to face issues concerning his/her condition in the future", "we had to convince him/her to have his/her surgery", "his/her friends started to ask him/her naturally about physical features that other peers do not have and he/she should be able to answer on his/her own", "he/she already had some knowledge of it from group meetings, so it was time anyways". 
The most common reason for their decision to inform siblings was that respondents thought they were mature enough to understand $(n=22 ; 44 \%$ ). The second most frequent answer was that they wanted the sibling to understand the reason for the frequent visits of the affected children to the hospital $(n=18 ; 30$ $\%)$. Other reasons included the following: "I wanted the sibling to understand about the genetic condition and needed his/hers cooperation", "I was dissatisfied with how differently I dealt with the child with the genetic conditions", "the sibling ridiculed the physical characteristics of the child with the genetic conditions", "the sibling started to notice the difference between the siblings of his/her friends and his/her own sibling", "I just naturally found myself wanting to talk ".

We asked respondents to select all the topics discussed with their children at the initial time of disclosing the diagnosis (Table 4). Respondents were also asked to add any additional reasons for their decision.

Table 4

Details of disclosed information

\begin{tabular}{|c|c|c|c|c|c|}
\hline & & \multicolumn{2}{|c|}{$\begin{array}{l}\text { Children with genetic condition ( } n= \\
67 \text { ) }\end{array}$} & \multicolumn{2}{|c|}{$\begin{array}{l}\text { Siblings }^{1} \\
(n=46)\end{array}$} \\
\hline \multicolumn{2}{|l|}{ Items } & $\%$ & $\mathrm{n}$ & $\%$ & $\mathrm{n}$ \\
\hline 1 & Diagnosis & 70 & 42 & 76 & 38 \\
\hline 2 & Symptoms & 73 & 49 & 92 & 46 \\
\hline 3 & Cause of genetic condition & 16 & 11 & 28 & 14 \\
\hline 4 & Management & 49 & 33 & 50 & 25 \\
\hline 5 & Heredity & 7 & 5 & 36 & 18 \\
\hline 6 & Reason for going to the hospital & 57 & 38 & 54 & 27 \\
\hline 7 & $\begin{array}{l}\text { Other (if possible, please explain in } \\
\text { detail) }\end{array}$ & 9 & 6 & 2 & 1 \\
\hline \multicolumn{6}{|c|}{ Note all items were multiple-choice answers. } \\
\hline
\end{tabular}

The most common detail for the decision of respondents to disclose the information on the genetic condition of their child was symptoms $(n=49 ; 73 \%)$, with diagnosis being the next most common $(n=$ 42; $63 \%)$. Other details included "the condition is no one's fault" and "everyone, not only you, has strengths and weaknesses". Some examples of other answers included intellectual disability, the reason for drawing blood every time they visited the hospital, and physical symptoms.

Regarding siblings, the most common detail of the disclosure of such information was symptoms ( $\mathrm{n}=$ $46 ; 92 \%)$ and the next most common was the diagnosis $(n=38 ; 76 \%)$ of the affected child. 
We asked respondents to list all the things they thought were important points when talking with their children (Table 5). Respondents were also asked to add any additional reasons they had.

Table 5

Important points when disclosing

\begin{tabular}{|c|c|c|c|c|c|}
\hline & & \multicolumn{2}{|c|}{$\begin{array}{l}\text { Children with genetic condition ( } n \\
=67 \text { ) }\end{array}$} & \multicolumn{2}{|c|}{$\begin{array}{l}\text { Siblings }^{1} \\
(n=46)\end{array}$} \\
\hline \multicolumn{2}{|c|}{ Items } & $\%$ & $n$ & $\%$ & $\mathrm{n}$ \\
\hline 1 & Be honest & 36 & 24 & 56 & 28 \\
\hline 2 & Keep it simple & 49 & 33 & 44 & 22 \\
\hline 3 & $\begin{array}{l}\text { Try to explain in a way that is easy to } \\
\text { understand }\end{array}$ & 67 & 45 & 66 & 33 \\
\hline 4 & Be direct; use appropriate terms & 3 & 2 & 6 & 3 \\
\hline 5 & Do not treat it as an abnormality & 27 & 18 & 36 & 18 \\
\hline 6 & Try to be relieved & 48 & 32 & 38 & 19 \\
\hline 7 & Treat it as "no big deal" & 25 & 17 & 24 & 12 \\
\hline 8 & Other (if possible, please explain in detail) & 15 & 10 & 8 & 4 \\
\hline \multicolumn{6}{|c|}{ Note all items were multiple choice answers. } \\
\hline \multicolumn{6}{|c|}{${ }^{1}$ This number reflects the siblings of affected children whose responders answered questionnaire I. } \\
\hline \multicolumn{6}{|c|}{ Note this number reflects children with genetic conditions. } \\
\hline \multicolumn{6}{|c|}{$\begin{array}{l}\text { Note the number of the siblings of affected children reflects the number of responders who answered } \\
\text { that they had disclosed information to the siblings of affected children in questionnaire I or } \\
\text { questionnaire II. }\end{array}$} \\
\hline \multicolumn{6}{|c|}{$\begin{array}{l}\text { Note respondents chose any number on a scale between } 0 \text { (lowest) and } 100 \text { (highest) as indicating } \\
\text { the degree of their feelings. *mean values for each items }\end{array}$} \\
\hline
\end{tabular}

The most frequently chosen important point when disclosing this information was their attempt to explain in a way that was easy to understand $(n=45 ; 67 \%)$. Keeping descriptions simple $(n=33 ; 49 \%)$ and trying to provide children with a sense of relief $(n=32 ; 48 \%)$ were the next most important points. Other important points included telling children that they were not alone, telling them that this was something to face together with the whole family, telling them that they would be helped by a lot of people, encouraging them to be positive and regard their condition as an aspect of their personality and individuality, telling them that there were various disorders, ad making it clear that everyone has their own challenges in life. 
In the case of siblings, the most frequently chosen important point when disclosing this information was that respondents tried to explain in a way that was easy to understand $(n=33 ; 66 \%)$. Being honest was the second most frequently chosen important point $(n=28 ; 56 \%)$. Other important points reported by respondents included: "I praised the sibling for also working hard during the surgery and hospitalization of the child with the genetic condition", "we told the sibling that if he/she would cooperate, the child with the genetic condition could become independent", "I told the sibling that the child with the genetic condition had an intellectual disability", and "children with genetic conditions might sometimes be restricted from engaging in things they want to do, but there should also be a bright future for them too".

We further asked whether respondents continued discussing with their children (affected and siblings) about the genetic condition after disclosing the diagnosis. Choices were never, sometimes, or always.

Regarding affected children, $12 \%(n=8)$ of respondents chose "never", whereas $88 \%$ of them chose "sometimes" ( $n=29 ; 45 \%)$ or "always" ( $n=28 ; 43 \%)$. The reasons for "never" were that respondents had just told the child, the child did not understand yet, the child did not talk about it, or the child did not ask about it. In the case of "sometimes", respondents had talked about the condition on occasions such as hospital visits, hospitalization, or group meetings, whenever the child asked about it, whenever the child experienced trouble regarding the condition, or when it had become a topic of conversation. The reasons for "always" were that respondents talked whenever the child was in trouble, on occasions such as participating in group studies, when watching TV, whenever the child asked about, whenever the child seemed to be concerned about symptoms, for the sake of the child's future, or because they had to provide the child with solutions for dealing with troubles regarding their conditions.

Regarding siblings, $10 \%(n=5)$ of respondents chose "never", whereas $90 \%$ of them chose "sometimes" $(n=23 ; 47 \%)$ or "always" ( $n=21 ; 43 \%)$. The reasons for choosing "never" included not asking about it, not seeming to care, or because parents did not view it as something special, so there was no need to talk about it anymore.

Respondents had received useful information on disclosing from attending doctors ( $n=41 ; 42 \%)$, from patients and family associates $(n=32 ; 32 \%)$, from the internet $(n=16 ; 16 \%)$, and from other sources ( $n$ $=10 ; 10 \%)$. Other useful information they relied on when disclosing this information included sources such as documents received from attending doctors, books, information about treatment and surgery, and support from family.

Respondents were asked to indicate the degree of their feelings by choosing any number on a scale of 0 to 100 , with the lower and upper extremes representing: "the outcome of disclosure was not good for us at all" and "the outcome of disclosure was extremely good for us" for item 1; "I really hesitated to tell them their diagnosis" and "I really wanted to tell them the whole story for a long time" for item 2; "I really regret telling them the diagnosis" and "I will never regret telling them the diagnosis" for item 3; "my family is not functioning well" and "family ties are stronger than ever before" for item 4; and "it's not easy to talk about it anymore" and "we can talk about it anytime we want to" for item 5. 
The lowest reported, highest reported, and mean values for each item were 50, 100, and 88 for item 1, 50 , 100, and 75 for item 2, 50, 100, and 95 for item 3, 40, 100, and 67 for item 4, and 0, 100, and 79 for item 5 . Many respondents felt disclosing information about the condition was a good thing and did not regret doing so (Figure 3). In contrast, a few respondents felt difficulty talking anymore with their families about the genetic condition.

\section{Questionnaire II: Respondents who had not disclosed the diagnosis to affected children yet}

Respondents were asked to select any of the 10 multiple-choice items denoting reasons for not disclosing the diagnosis. Respondents ( $n=91 ; 58 \%$ ) were also asked to add any additional reasons they might have had. The average age of children with a genetic condition was 9.8 years old.

The most common reason for not disclosing the diagnosis was that the children were not mature enough to understand ( $n=70 ; 77 \%)$. The next most frequent answer was "other" ( $n=28 ; 31 \%)$, followed by "had never been asked about symptoms" ( $n=23 ; 25 \%$ ). As it concerns the reasons given for "other", 22 (79 \%) out of 28 respondents mentioned difficulty with understanding because of intellectual disability. Four respondents talked to their children about symptoms, the reason for hospitalization, and the reasons for visiting the hospital, but not the diagnosis of the genetic disease. One responder was afraid that if they disclosed the disorder, the child would unintentionally expose its condition to others, which was not desired by the parents. Another responder answered that they did not feel the need to disclose the diagnosis at this point.

We asked respondents whether they would disclose information to their children in the future and their reasons for their answers.

Regarding children with genetic conditions, 68 (75\%) out of 91 respondents answered that they plan to disclose the diagnosis in the future, $24 \%(n=22)$ answered that they would not, and $1 \%(n=1)$ answered that they were not sure.

Reasons for disclosing information in the future included the following: "he/she can live a better life if he/she knows, " "he/she will be able to get appropriate support if he/she knows the characteristics of the disorder", "we want him/her to live life with a positive outlook by understanding and accepting the disorder", "we want him/her to be able to communicate his/her needs and ask for help from others when needed", "we will tell him/her why he/she is different from his/her peers when he/she notices and asks about that", "we will tell him/her what he/she should know when he/she starts asking because it's not a matter that should be hidden", "it will be necessary when getting married and starting a family".

Reasons for not disclosing the information included the difficulty of the child to understand because of intellectual disability, the unknown time by which the child would be able to understand, or the belief of respondents that it was not a matter to deal with proactively. 
One responder answered, "I am not sure whether to disclose the information even in the future because nobody knows when they will have grown enough to understand their diagnosis. If they could understand, I would want to tell them, but no one knows when that will be".

Regarding siblings, 34 (45\%) out of 75 siblings had already been informed, 35 (47\%) respondents planned to disclose the information in the future, four (5\%) respondents would not disclose the information, and two (3\%) declined to answer.

We asked respondents to specify the age at which they would disclose this information to the affected child in the future. Regarding children with genetic conditions, 32 out of 68 respondents ( $47 \%$ ) planning to tell the child about their condition answered "uncertain"; this was the most frequent answer. Similar results were obtained for the siblings. The second most frequent answer was "third to fourth grader in elementary school (9-10 years) ". No one mentioned "19 years old or older".

The most frequent answer to whom would primarily disclose the diagnosis to affected children was both parents $(n=43 ; 58 \%)$, with the mother being the second most frequent answer $(n=22 ; 30 \%)$, whereas the father constituted only $7 \%(n=5)$, and others, such as attending doctors and grandparents constituted $4 \%(n=3)$ and $1 \%(n=1)$ of all answers, respectively. Considering siblings, the most frequently chosen answer was also both parents $(n=36 ; 51 \%)$, with the mother being the second most frequent answer $(n=29 ; 42 \%)$, followed by the father $(n=2 ; 3 \%)$, and finally, others, such as attending doctors $(n=2 ; 3 \%)$.

\section{Discussion}

We conducted a survey on parents/caregivers of children with genetic conditions regarding the disclosure of information about their genetic condition, and found that many respondents who had disclosed such information had not regretted this and felt it was an ultimately good decision despite the low rate of disclosure (less than half; $n=67,42 \%$ ) compared with that of previous studies. For instance, in previous studies 130 out of 139 participants reported sharing such information, with $90.6 \%(n=102)$ sharing it with affected children [8], [9]. We also found that many respondents $(n=68,75 \%)$ who had not yet disclosed information to their children planned to do so in the future.

In our study, respondents whose children had a genetic condition, such as BWS or PWS, had higher rates of disclosing information compared with those of children with other genetic conditions. We assumed that the level of intellectual disability of the child might affect whether this information would be disclosed to them. Children with BWS have no intellectual disability, and visit the hospital regularly (e.g., abdominal ultrasound) even in the absence of symptoms; therefore an explanation for the reason of these visits might be highly required. Children with PWS require a strong effort or cooperation from the individual in terms of dietary management, which likely influences the high necessity for explanation. However, we were unable to identify the reasons behind the differences in the rate of disclosure for these genetic conditions, a possible limitation of this study. 
In our study, respondents most frequently disclosed the diagnosis in early childhood during preschool ages (4-6 years old). Szybowska [10] reported that adolescents prefer to receive information about the genetics of their condition at a much younger age (6-10 years old) than when they are usually seen for genetic counseling. Being informed at an early stage of childhood might help them understand the nature of their health condition and its more efficient management.

Many respondents in our study talked about diagnoses, symptoms, and management of their children, but rarely about the cause of a genetic condition or its inheritance, which seemed to concur with the notion reported by Gallo [8], who pointed out that parents do not want to address the potential negative consequences of the condition or its inheritance.

Regarding disclosing diagnoses to children, Dennis[ 9] recommended using simple and direct language and avoiding ambiguous descriptions or complex terminology. Dennis also recommended that parents be honest with the child and stay positive. In a study about informing girls with Turner syndrome regarding their medical condition, Takahashi [11] reported that most parents seemed to share information with their child in a positive manner. Respondents in our study tried to explain in a way that was easy to understand, honest, and positive. They also tried to dispel worries and anxiety as much as possible.

Metcalf et al. [4] reported that while parents sometimes reported feeling afraid to discuss their child's emotions of worry, depression, frustration, or embarrassment, parents who openly communicated with their children never expressed regret about discussing the genetic condition with their families. In our study, many respondents continued to discuss the genetic condition of the affected children following disclosure.

Dana et al. [12] reported that many parents who had disclosed the diagnosis to their child with chromosome 22q11.2 deletion syndrome felt they could have benefited from additional advice from professionals to increase their confidence and success of the disclosure. Societal organizations, such as associations of patients and families can play a very important role in helping to solve the problems parents by supporting each other [11]. In our study, nearly half of respondents who had disclosed the diagnosis to their affected children thought that advice from the attending doctor on what and how to disclose the information was helpful. They also received useful information from the associations of patients and families.

Dana et al. [12] also reported that parents who had not informed children with chromosome 22q11.2 deletion syndrome were uncertain about the words to use, how to initiate the conversation, or were concerned about the level of understanding of their child. In our study, respondents who had not yet disclosed information tended to plan to disclose the diagnosis when the children grew to be able to understand what they should know. The most common reason for not disclosing was the intellectual disability of the child, which was fully understandable.

There were several limitations to this study. The time from diagnosis varied, and the ages of children ranged from 4 to 28 years. Whether parents had disclosed information to their affected children and 
siblings could vary depending on the time from diagnosis and age of children. All children included in the study had a genetic condition, but some had only moderate or no intellectual disability. The extent of a child's intellectual disability may also affect the disclosure of information to them. It is difficult to determine the extent to which this study can be generalized to a wider population of families affected by these and other genetic conditions. Additionally, this study did not explore the perspectives of children with genetic condition or their siblings. Further study on disclosing information about the diagnoses of children with a focus on the children themselves is necessary for parents who are planning to disclose information to their children, especially in Japan.

\section{Declarations}

\section{ACKNOWLEDGEMENTS}

This study was supported by Division of Medical Genetics, Saitama Children's Medical Center.

\section{Funding}

This work was supported by The Grant of Saitama Children's Medical Center 2019-A6 and Research on Rare and Intractable Diseases from the Ministry of Health, Labour and Welfare, Japan.

\section{Conflict of interest}

The authors have no conflicts of interest to declare.

\section{Data availability statement}

The data in this work will be available under Creative Commons Attribution Non-Commercial -NoDerivs License

\section{References}

1. Fanos, J. H. \& Puck J. M. Family pictures: growing up with a brother with X-linked severe combined immunodeficiency. American Journal of Medical Genetics. 98, 57-63 (2001).

2. Gallo, A. M., Augst D. B. \& Hadley, E. Parents sharing information with their children about genetic conditions. Journal of Pediatric Health Care, 19, 267-275 (2005).

3. Holt, K. What do we tell the children? Contrasting the disclosure choices of two HD families regarding risk status and predictive genetic testing. Journal of Genetic Counseling, 15, 253-265 (2006).

4. Metcalfe, A., Coad, J., Plumridge, G., Gill, P., Farndon, P. Family communication between children and their parents about inherited genetic conditions: a meta-synthesis of the research. European Journal of Human Genetics, 16, 1193-1200 (2008). 
5. Gaff, C. L. et al.. Process and outcome in communication of genetic information within families: a systematic review. European Journal of Human Genetics, 15, 999-1011 (2007).

6. Metcalfe, A., Plumridge, G., Coad, J., Shanks, A., Gill, P. Parents' and children's communication about genetic risk: a qualitative study, learning from families' experiences. European Journal of Human Genetics, 19, 640-646 (2011).

7. Braun, V. \& Clarke, V. Using thematic analysis in psychology. Qualitative Research in Psychology, 3, 77101 (2006).

8. Gallo, A. M., Augst D. B., Knafl K. A., Twomey, J. G., Hadley, E. Health care professionals' views of sharing information with families who have a child with a genetic condition. Journal of Genetic Counseling, 19, 296-304 (2010).

9. Dennis, A., Howell, S., Cordeiro, L., \& Tartaglia, N. "How should I tell my child?" Disclosing the diagnosis of sex chromosome aneuploidies. Journal of Genetic Counseling, 24, 88-103 (2015).

10. Szybowska, M., Hewson, S., Antle B. J., and Babul-Hiriji, R. Assessing the informational needs of adolescents with a genetic condition: What do they want to know? Journal of Genetic Counseling, 16, 201-210 (2007).

11. Takahashi, N. Questionnaire about informing Turner girls of the medical condition. Clinical Pediatrics Endocrinology, 14(Suppl 24), 25-30 (2005).

12. Dana, F., Kelly, S., Sonja, E., Hooper, S. R., \& Shashi, V. Assessment of parental disclosure of a $22 q 11.2$ deletion syndrome diagnosis and implications for clinicians. Journal of Genetic counseling, 21, 835-844 (2012).

\section{Figures}




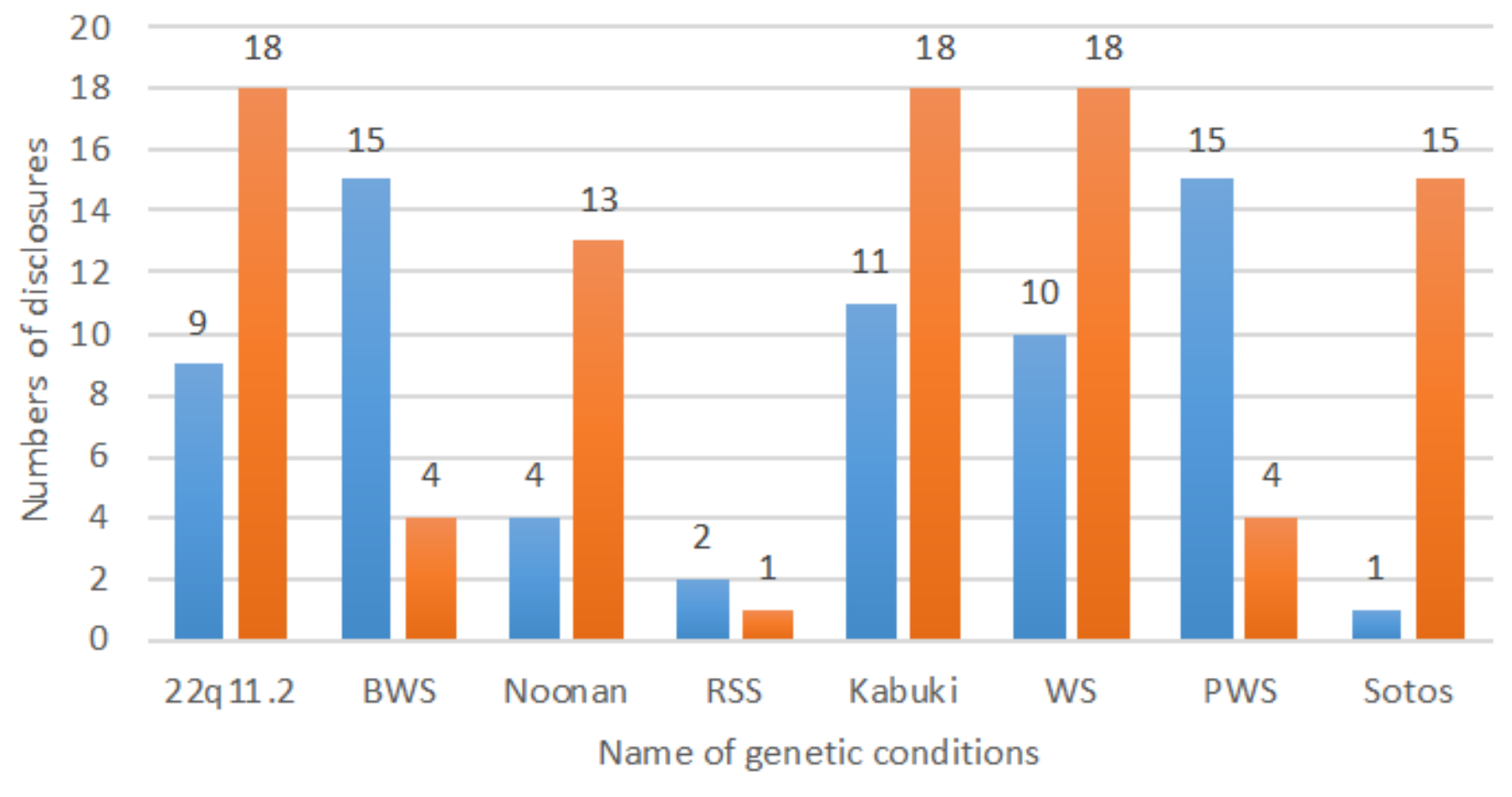

Disclosed $\quad$ Not disclosed

Figure 1

Number of disclosures by genetic condition Note this number reflects children with genetic conditions. 


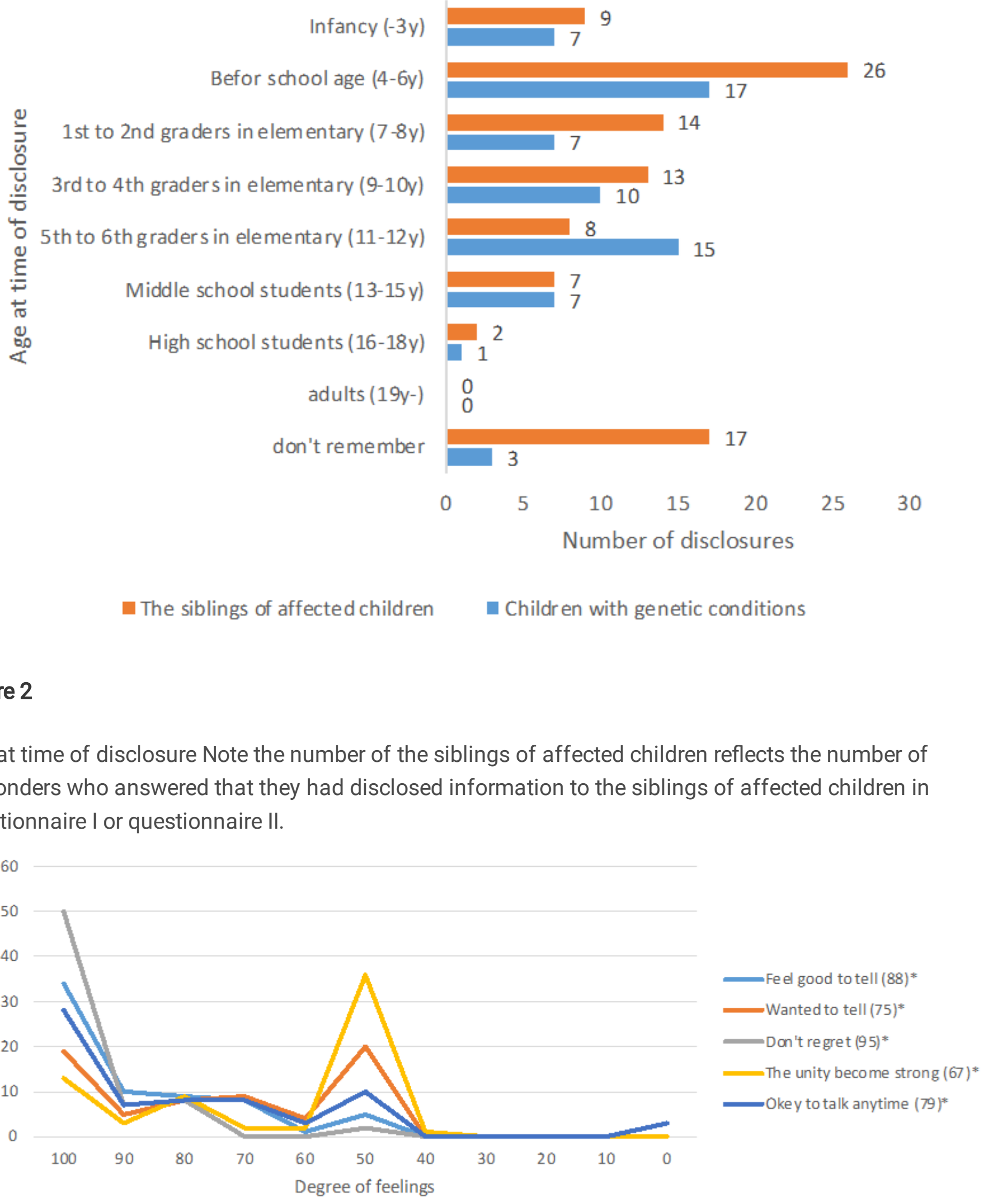

Figure 3 
Degree of feelings Note respondents chose any number on a scale between 0 (lowest) and 100 (highest) as indicating the degree of their feelings. *mean values for each items 